\title{
Research on the Relationship Between Teaching and Scientific Research in the Research University
}

\author{
Suolan Liu and Lizhi Kong* \\ Changzhou University, Jiangsu, China, 213164 \\ lan-liu@163.com
}

Keywords: Teaching, Scientific research, Teachers, Students, Relationship, Measures

\begin{abstract}
In research universities, teaching is the basis of scientific research, scientific research is the development and improvement of teaching. Teaching and scientific research should be dialectically united, complementary and mutually reinforced. The research university must constantly improve the educational ambitions and take scientific research as a breakthrough to promote the undergraduate teaching with scientific research achievements. Encourage teachers to integrate the latest research results into teaching, so as to continuously enrich the teaching contents. Advocate original creative research and research-based teaching. Cultivate high-level creative talents through high-level teaching and scientific research.
\end{abstract}

\section{The Background of the Problem}

At present, there is a common phenomenon in research universities that is most teachers pay great attention on scientific research while attach little importance to teaching. How to balance scientific research and teaching is an importance problem, which has direct influence on the development of the university. Educator Joseph. David ever said scientific research and teaching are far from natural matches, but the two will compose to be an integral whole in certain condition. Since the $19^{\text {th }}$ century, many universities have established education research institutes and scientific research institutes. Teaching knowledge is not the sole main responsibility of university. These universities advocate the unification of teaching and research. They believe that the research university should have two basic responsibilities including teaching and research. Especially, the research should be original research and teaching should be research teaching. High-level creative talents should be cultivated through these kinds of high-level teaching and scientific research.

However, in our country there are only a few research universities who can truly and effectively combine teaching with scientific research. Due to various factors such as economy, there are two misconceptions about the relationship between the higher education and teaching \& research. One is teacher pays great attention on scientific research, while attaches little importance to teaching. For examples: some teachers would rather spend most of their time doing scientific research, but are unwilling to undertake basic teaching tasks. They are very positive about publishing papers, but do not want to discuss teaching method and are less glad to do teaching reform and exploration. Or, some teachers are interested in the scientific research achievements of domestic or foreign counterparts, but do not care the achievements of teaching. What is more, teachers are proud of the scientific achievements they have made, but they are not impressed by the teaching results. One cause of these phenomena may be that scientific research achievements have been an important criteria to evaluate the comprehensive strength of a university. In order to effectively carry out scientific research, some universities have proposed a series of policies, such as economic benefits for research achievements. In addition, some universities have made research achievements as an indispensable condition for the evaluation of teachers' titles. Another is teacher pays great attention on teaching, while attaches little importance to scientific research. Our traditional education thought sets transmitting wisdom, imparting knowledge and resolving doubts as university's missions. Its ultimate goal is letting students remember and understand what they taught. Therefore, quite a few teachers believe that well teaching book's knowledge is their mission. Actually, the main reason for this misconception is that there is not accurate understanding of the essence of 'teaching'. Now our country in the period of 
high-speed development, and science and technology should be the original driving force. This requires our universities to strengthen scientific research building to push scientific technology advancing. At the same time, it needs higher education equip students with the latest knowledge. Teach students how to solve problems with creative ability, and encourage students to learn scientific research methods and put in practices. This requires teachers must have certain scientific research ability and master scientific methods. Only in this way can meet the needs of cultivating talents for modernization construction of China.

\section{Discuss on the Relationship Between Teaching and Scientific Research}

Teaching and scientific research are two hot topics in university. How to effectively handle the relationship between the two is very important to the development of the university. Due to the limitation of time and energy, some teachers lament that teaching and scientific research are two irreconcilable contradictions. In fact, this idea is one-sided, the two are dialectical and unified.

The Effect of Scientific Research on Teaching. Science and technology develops with each passing day. New achievements, theories and application require university teachers must stand in the forefront of knowledge development so as to update and supply knowledge to cultivate innovative talents. Scientific research is the most direct and effective way to obtain new knowledge. Only taking part in scientific research can ensure the teacher being in academic frontiers, keeping the academic level up and improving teaching quality. Then, scientific research is an important mean to cultivate innovative talents. In research universities, scientific research has become a key way of education. It is impossible to cultivate highly qualified and highly creative talents by only classroom teaching.

The Effect of Teaching on Scientific Research. Teaching is very important to scientific research. First, teaching provides new growth points for research. On one hand, research projects come from social practice. But on the other hand, they may come from every courses in teaching activities. Students often put forward some new insights and enlightening problems, which encourages teacher to think and organize strength to do research. Then, teaching helps teacher to systematize scientific knowledge and organize his thoughts for research activities. So, teaching can be viewed as the propagation and verification of scientific research. Scientific research creates knowledge, and teaching spreads knowledge. The combination of the two enables scientific research to be incorporated into teaching contents, and makes it relevant to the original knowledge system.

The Need of Dialectical Unity of Teaching and Research. Statistics suggest that there is great relationship between well teaching and doing scientific research for a teacher in university. Teacher's improvement is not by listening in a class, but by doing research. Studying while researching and learning what you need is the main method. Research is the fundamental way to train teachers. In the course of teaching, we should examine and analyze the problems of teaching theory and teaching practice with the eyes of an researcher. Profound consideration of their own behavior, investigation the appeared problems and summarization the accumulated experience will help to form regular understanding. This kind of 'action research' can organically combine teaching with scientific research. It is the precondition for a teacher to change from 'teacher' to 'educator', and also is the basis for continuous improvement.

\section{Some Measures to Advance Dialectical Unity of the Two Aspects}

For a university, teaching quality is the lifeline and scientific research is the source of development. Low teaching quality will endanger the survival of the university. Lack of scientific research will make school stagnant, or even seriously affect the quality of teaching. In research university, teaching and scientific research should be mutual influenced and promoted. Teachers need to assume the dual tasks of teaching and research. Despise any part is not conducive to the development of university, teachers and students. Teachers have to adjust the relationship between the two in time so as to promote their own comprehensive abilities.

Establish a Reasonable and Effective Teaching \& Scientific Research Management system. To create good learning and research environment for both students and teachers we should integrate 
teaching management with scientific management. Improve knowledge level and research ability in teaching with learning. Besides, teachers should change their ideas from teaching scientific contents to scientific methods, cultivate students innovative consciousness and spirit, so as to enable students to become knowledge explorers and creators instead of only receivers. University's management system is usually formed and developed from the original teaching management system, which cannot meet the needs of the current development. Therefore, our universities should build a set of new management system, which can not only satisfy the requirements of teaching and research, but also advance and guarantee the benign interaction between teaching and research.

Encourage the Development of Research-based Teaching Methods. We should introduce the latest research achievements into the construction of undergraduate courses, improve and perfect the experimental teaching system, and pay attention to improve students' practical ability. Encourage students to take part in academic reports and discussion so as to broaden their knowledge and stimulate research interesting. At the same time, we may create research projects and practice opportunities for them and encourage cooperation among students or students and teachers.

Fuse Teaching and Research into Disciplinary Construction. The level of teaching and researching always depends on the level of disciplinary construction. Disciplinary construction is the basis and carrier for carrying out the teaching, scientific research and so on. It is also an important symbol of university's running level and social reputation. As a result, teaching and research should be unified with the framework of disciplinary construction. Our universities should adjust the weights between teaching and research according to the resources condition and developments requires of disciplinary construction.

Establish a Scientific Evaluation Mechanism of Teaching and Scientific Research. The university's Administrators should insist on the people-oriented management philosophy. The establishment and implementation of a series of scientific incentive management mechanism can effectively stimulate the enthusiasm of teaching and research. In order to solve the imbalance between teaching and scientific research, we must build a scientific evaluation mechanism. Give a comprehensive evaluation of teacher's teaching ability and scientific research level through every evaluating indicator. Should pay equal attention to the evaluation of teaching and research, try to be objective, justice and reasonable. In the management of scientific research, we should strengthen the assessment of achievements quality instead of quantitative statistics. In the management of teaching, we should improve the scientific and feasibility of teaching assessment. Appropriately promote the weight of teaching performance in the evaluation of teaching and professional titles. Through scientific evaluation system and reasonable policy guidance, teachers should be guided to correct the attitude of teaching and research and improve the levels, so as to solve the imbalance problem fundamentally.

\section{Conclusion}

Teaching and scientific research are two main functions of modern universities. Research university is the inevitable trend and requirements of university development. It takes the responsibility of mass education and elite education. It is the main power of training senior specialized technical personnel. With the opening of Chinese education market, higher education is facing fierce competition. Universities are also facing opportunities and challenges. But, as the main fore of the development of science and technology, universities should play a leading role in the process of building a 'learning' society. So, it is necessary to cultivate a contingent of high-quality research-based teaching talents. Effectively combining teaching and scientific research in the condition of disciplinary construction will play an important role in the long-term development of the university.

\section{Acknowledgements}

This work is supported by the project of Changzhou University (No.2015XSJ11) and project of Changzhou science and education town (No.CDGZ2016002). 


\section{References}

[1] Y Song, L Yang. Evaluation research on teaching and scientific research status of teaching and research university teachers[J]. Journal of Chongqing jiaotong university, 2014, 106-108.

[2] S Yang, Y Sun. On the interation of teaching and scientific research in the institutions of higher lerning [J]. Journal of hebei normal university , 2002,21-23

[3] Michille. University teachers' innovative teaching behavior and the relationship between the innovative ability of college students Investigate [J]. Journal of teaching research, 2013, 15-18.

[4] Y Huang. University research management policy and system in our country [J]. Journal of education and economy, 2015, 3-8.

[5] R Ye. The cultivation of teaching and scientific research teachers[J]. Innovation and development, 2016(1), 31-38

[6] W Ping. Local colleges and universities' young teacher innovation ability development's situation and countermeasure research[J]. Journal of China university of education, 2015:73-76.

[7] Y Zheng, Y Wu. Approaches for improving professors' teaching arts in top universities[J]. Journal of UESTC(Social sciences edition), 2010(12):107-109.

[8] J Li, J Lin. Promoting the cultivation of innovative talents through combination of practical teaching and academic competition[J]. Experimental Technology and Management, 2011, 28(11):1-4

[9] Z Feng. Several 1ssues Concerning lnnovmion Consciousness[J]. Journal of Hunan Economic Management Cadre College, 2002(1):6-10.

[10] C Pan. Training students practical innovatin ability by building a four level discipline competion platform. ICETIS 2013,1008-1011

[11] B Fei. Study on countermeasures for cultivation innovation ability for college and university students[J]. ICIMTR 2013, 213-217

[12] Y Guo. Deepening the reform of medical teaching and cultivating scientific research talents. Journal of clinical medical, 2016,3:11052-11053.

[13] R Sun, X Xue. Improve the quality of undergraduate teaching by introducing scientific research mode. Journal of higher education in science \& technology, 2010,12: 99-100

[14] S Liu, LKong. Research on the Relationship and measures of innovative ability between students and teachers, Advances in Computer Science Research, 2017, 59: 642-645 